\section{Journal of Polytechnic POLITEKNK DERGISI}

\section{POLITEKNIK DERGISI}

JOURNAL of POLYTECHNIC

\title{
İnme rehabilitasyonunda kullanılabilecek kablo ve yay tahrikli giyilebilir bir el bileği egzersiz cihazı tasarımı
}

\section{Design of a cable and spring-driven wearable wrist exercise device for stroke rehabilitation}

Yazar(lar) (Author(s)): Kasım SERBEST, Murat ÇILLI, Mustafa Zahid YILDIZ, Osman ELDOĞAN

Bu makaleye șu ssekilde atıfta bulunabilirsiniz(To cite to this article): Serbest K., Çilli M., Yıldız M. Z. ve Eldoğan O., “Inme rehabilitasyonunda kullanılabilecek kablo ve yay tahrikli giyilebilir bir el bileği egzersiz cihazı tasarımı”, Politeknik Dergisi, 20(4): 953-959, (2017).

Erişim linki (To link to this article): http://dergipark.gov.tr/politeknik/archive 


\title{
İnme Rehabilitasyonunda Kullanilabilecek Kablo ve Yay Tahrikli Giyilebilir Bir El Bileği Egzersiz Cihazı Tasarımı
}

\author{
Araştırma Makalesi / Research Article \\ Kasım SERBEST $^{1^{*}}$, Murat ÇİLLi ${ }^{2}$, Mustafa Zahid YILDIZ ${ }^{3}$, Osman ELDOĞAN ${ }^{1}$ \\ ${ }^{1}$ Sakarya Üniversitesi, Teknoloji Fakültesi, Mekatronik Mühendisliği Bölümü, Sakarya, TÜRKIYYE \\ ${ }^{2}$ Sakarya Üniversitesi, Spor Bilimleri Fakültesi, Antrenörlük Eğitimi Bölümü, Sakarya, TÜRKIYE \\ ${ }^{3}$ Sakarya Üniversitesi, Teknoloji Fakültesi, Elektrik ve Elektronik Mühendisliği Bölümü, Sakarya, TÜRKIYE \\ (Geliş/Received : 24.10.2016 ; Kabul/Accepted : 12.11.2016)
}

\begin{abstract}
ÖZ
İnme, her yıl milyonlarca kişiyi etkilemektedir. Bu kişilerin çoğu, hareket kabiliyetlerini geri kazanabilmek için rehabilitasyona ihtiyaç duymaktadırlar. El kaslarının robotik temelli rehabilitasyonuna yönelik çok sayıda cihaz önerilmiş olmasına rağmen bu cihazların hala geliştirilmesi gereken yönleri vardır. Önceki cihazlarda kuvvet ve hareket aktarımı için kullanılan yöntemlerin bir takım olumsuz yönleri bulunmaktadır. Bunlardan biri, cihazlarda kullanılan mafsallar ile el ve el bileği eklemlerinin dönme merkezlerinin tam olarak hizalanamamasıdır. Bu durum, vücut eklemleri üzerinde kesme kuvvetleri oluşturmaktadır. Dönme merkezlerini hizalamak için uygulanan yöntemlerin bazı dezavantajları bulunduğundan yeni uygulamalara ihtiyaç vardır. Bu çalışmada, el bileği egzersizlerini gerçekleştirmek amacıyla yeni bir cihaz önerilmektedir. Cihaz, hareket ve kuvvet aktarımını kablo ve yay tahriki ile yapmaktadır. Böylece dönme merkezlerinin hizalanması sorunu yaşanmamaktadır. Cihaz, pasif ve aktif egzersizlere olanak sağlamaktadır. Cihazın ev ortamında kullanıma uygun, taşınabilir ve düşük maliyetli olması amaçlanmıştır. Geliştirilen cihazın, rehabilitasyon maliyetlerini azaltması ve tedavi sürecini kısaltması beklenmektedir. Cihaz, inme rehabilitasyonun yanı sıra sinir yaralanması, sinir sıkışması, tendon yaralanması, kırıklar ve spor yaralanmaları gibi durumlarda da kullanılabilir. Düşük maliyetli olması beklenen cihazın, ticarileştirilmesi durumunda tıbbi cihazlar alanında dış pazarlara bağımlı ülkemizin rekabet gücüne katkı yapması beklenmektedir.
\end{abstract}

Anahtar Kelimeler: El rehabilitasyonu, inme, egzersiz cihazı.

\section{Design of a Cable and Spring-Driven Wearable Wrist Exercise Device for Stroke Rehabilitation}

\begin{abstract}
Stroke affects millions of people every year. Most of them need rehabilitation to recover their mobility. Although a lot of robotic based devices have been suggested for rehabilitation of the hand muscles, these devices still need some improvements. Methods using for transmitting movement and force in previous devices have some disadvantages. One of them is misalignment on the centre of rotation between joints used in devices and joints of the hand and the wrist. This situation causes a shear force on the joints of human limbs. To resolve these problems new approaches should be proposed. In this study a novel device is suggested to perform the wrist exercises. The device has a cable and spring-driven system for transmitting movement and force. Thus, it does not cause the alignment problem on the centre of rotation. The device allows both passive (assistive) and active exercises. It is aimed that the device is suitable for home use, portable and low cost. The proposed new device expected to reduces the rehabilitation cost and therapy period. The device can be used for other situations such as nerve injury, nerve compression, tendon injury, fracture and sport injury besides stroke rehabilitation. If this low cost device can be commercialized, it is clear that, it may contribute to Turkey competitiveness capacity on the global medical markets.
\end{abstract}

Keywords: Hand rehabilitation, stroke, exercise device.

\section{GIRIŞ (INTRODUCTION)}

Orta yaş ve üzerindeki kişilerde görülme sıklığı yüksek olan rahatsizlıklardan biri olan inme, dünya genelinde her y1l yaklaşık 15 milyon kişinin yaşadığ bir hastalıktır. Bu kişilerin yaklaşık 9 milyonu hayatta kalmaktadır ve reha-

*Sorumlu Yazar (Corresponding Author)

e-posta: kserbest@sakarya.edu.tr bilitasyona ihtiyaç duymaktadırlar [1]. İnme sonrası karşılaşlan önemli sorunlardan biri, vücudun belirli bir yarısında meydana gelen hareket ve his kayıplarıdır. Tedavi merkezlerinde farklı yöntemler kullanılarak inme rehabilitasyonunda başarılı sonuçlar alınmakta ve hastalar gündelik işler sırasında ihtiyaç duydukları hareketleri yapabilir hale gelmektedirler.

Rehabilitasyon amaçlı hizmet veren merkezlerde uygulanan tedavi yöntemleriyle başarılı sonuçlar alınmasına 
rağmen buradaki süreçlerde bir takım sınırlılıklar ve dezavantajlar bulunmaktadır. Bunlar; belirli bir merkeze ve uzman kişilere olan bağımlılık, rehabilitasyon hizmetin-
Rehabilitasyonda kullanılan yöntemlerden biri mekatronik temelli cihazlar kullanarak hastaya hareketleri pasif veya aktif olarak yaptırmaktır. Dünya genelinde son yıl-

Çizelge1. Dönme merkezlerini hizalamak için uygulanan yöntemler (Methods for alignment of centre of rotation)

\begin{tabular}{|c|c|c|c|}
\hline Ref. & Yöntem & Görsel & Açıklama \\
\hline [9] & $\begin{array}{l}\text { Dönme merkezlerini } \\
\text { doğrudan eşleştirme. }\end{array}$ & & $\begin{array}{l}\text { Çok kullanılan yöntemlerden } \\
\text { biridir. Parmakların veya bileğin } \\
\text { yan yüzüne yerleştirildiğinden } \\
\text { fazladan yer kaplamaktadır. Ayrıca } \\
\text { tüm parmaklar için uygulanmak } \\
\text { istenirse, yerleştirilecek uygun yer } \\
\text { bulmak çok zordur. }\end{array}$ \\
\hline [10] & $\begin{array}{l}\text { Hem dönme hem de } \\
\text { öteleme hareketine izin } \\
\text { veren mekanizmaların } \\
\text { kullanımı }\end{array}$ & & $\begin{array}{l}\text { Örneğin çift parallelogram } \\
\text { mekanizması sayesinde aynı eklem } \\
\text { üzerinde hem öteleme hem de } \\
\text { dönme hareketi yapılabilir. Uzuv } \\
\text { üzerinde dikey yönde çok yer } \\
\text { kaplamaktadırlar. }\end{array}$ \\
\hline [11] & $\begin{array}{l}\text { Fazladan mekanizma } \\
\text { kullanımı }\end{array}$ & & $\begin{array}{l}\text { Fazladan mekanizma kullanımı ile } \\
\text { sistemin serbestlik derecesi } \\
\text { artırılarak hem dönme hem de bir } \\
\text { miktar öteleme hareketi yapılabilir. } \\
\text { Uzuv uzunlukları değiştirilerek } \\
\text { hareket açıklığı ayarlanabilir. }\end{array}$ \\
\hline
\end{tabular}

den sınırlı sayıda kişinin yararlanabilmesi, rehabilitasyon sürecindeki nispeten yüksek maliyet ve rehabilitasyon hizmetine erișimde yaşanabilecek zorluk şeklinde sıralanabilir. Bu gibi sorunlar ev ortamında rehabilitasyona yönelik uygulamaların geliştirilmesini gerektirmektedir. Dünya Sağlık Örgütü'nün yayınladığı Dünya Engellilik Raporu'nda [2] yardımcı teknolojilerin kullanımının artmasıyla, rehabilitasyon sürecindeki bakım ve destek maliyetlerinin düşebileceğine vurgu yapılmaktadır. $\mathrm{Bu}$ öngörüyü destekleyen nitelikte bir çalışmada Butler ve ark. [3] inme rehabilitasyonunda kullanılan aktif eyleyicili bir cihazın rehabilitasyon maliyetleri üzerindeki etkilerini incelemişlerdir. Belirli bir ücret karşılığı kiralanan ve evde kullanılabilen cihaz sayesinde rehabilitasyon sürecinin toplam maliyetinde yaklaşık \%55 oranında azalma tespit edilmiştir. Maliyetin yanı sıra, ev ortamında rehabilitasyon süreçleri ile yüksek yoğunluklu (gün içinde çok kez tekrar edilen) egzersizler gerçekleştirmek mümkündür. Böylece, iyileşme süreci hılandırılmaktadir $[4,5]$. larda yapılan çalışmalar sayesinde özellikle el rehabilitasyonunda kullanılabilecek giyilebilir ve ev ortamında kullanılabilir robotik cihazların geliștirilmesi hız kazanmıştır [6]. Farklı parmak ve bilek egzersizlerini gerçekleştirebilen cihazlarda elektrikli, pnömatik ve hidrolik eyleyiciler ve şekil hafızalı malzemelerden üretilmiş eyleyiciler kullanılmakla birlikte ev ortamında kullanıma uygun cihazların elektrik enerjisi ile çalışması beklenmektedir. İlaveten cihazların hafifliği ve estetik görünümlü olması önemli bir etkendir [7]. Ancak ev ortamında kullanılacak cihazların tasarımında dikkat edilmesi gereken en önemli nokta güvenliktir. Mekanik açıdan ele alındığında aktif eyleyicileri bulunan cihazların hareket aktarımında dikkat edilmesi gereken husus, kullanıcının eli üzerine giydirilmiş cihazın mafsalları ile el ve el bileğindeki eklemlerin hareketinin tam olarak birbirini karşılamasıdır. El ve el bileğinde yer alan eklemler polisentirik yapıdadırlar ve dönme hareketi sırasında dönme merkezleri değişmektedir [8]. Cihazda bulunan mekanik mafsalların ve kullanıcının eklemlerinin tam 
olarak hizalanamaması durumunda kesme kuvvetleri ortaya çıkmakta ve bu durum kullanıcıya zarar vermektedir. $\mathrm{Bu}$ sorunu ortadan kaldırmak amaciyla uygulanan bazı yöntemler Çizelge 1'de yer almaktadır. kolaylaştırmasıdır. Agrawal ve ark. çalışmalarında kol bölgesini referans alarak dirsek ve omuz egzersizlerini sağlayan bir cihaz önermektedirler.

$\mathrm{Bu}$ çalışmada, inme sonrası rehabilitasyonda kullanılabilecek, el bileği egzersizlerini gerçekleştiren,

Çizelge 1. Devamı (Continue)

\begin{tabular}{|c|c|c|c|}
\hline Ref. & Yöntem & Görsel & Açıklama \\
\hline [12] & $\begin{array}{l}\text { Tendon-tahrikli } \\
\text { mekanizma kullanımı }\end{array}$ & & $\begin{array}{l}\text { Tendon görevi gören, parmağın } \\
\text { üst ve alt tarafina yerlestirilen } \\
\text { kablolar kullanılarak mekanik } \\
\text { mafsalların yol açtığı sorun } \\
\text { ortadan kaldırılabilir. }\end{array}$ \\
\hline [13] & $\begin{array}{l}\text { Yumuşak (soft) eyleyici } \\
\text { kullanımı }\end{array}$ & & $\begin{array}{l}\text { El veya bilek yüzeyini saran } \\
\text { yumuşak eyleyiciler ile mekanik } \\
\text { mafsallar kullanmadan } \\
\text { hareketleri gerçekleştirmek } \\
\text { mümkündür. }\end{array}$ \\
\hline [14] & $\begin{array}{l}\text { Distal uzva sabitlenmiş } \\
\text { mekanizma kullanımı }\end{array}$ & & $\begin{array}{l}\text { Sadece distal uzva sabitlenmiş } \\
\text { (örneğin parmaklar için distal } \\
\text { falanks) seri mekanizmalar } \\
\text { kullanarak kesme kuvvetlerinin } \\
\text { oluşumu engellenebilir. }\end{array}$ \\
\hline
\end{tabular}

Dönme merkezlerini hizalamak amacıyla kullanılan mekanizmalar veya mekanik elemanlar (dişliler, kasnaklar vb.) el üzerine yerleştirildiğinden çok yer kaplamakta ve hantal bir görünüme sebep olmaktadırlar. Yine uzuv üzerine yerleştirilen yumuşak eyleyicili sistemler, çoğunlukla hidrolik veya pnömatik prensiplere göre çalıştıklarından ilave donanıma ihtiyaç duymaktadırlar [15]. Bu durum ev ortamında kullanımı zorlaştırmaktadır. Eldeki tendonların çalışma prensibine göre tasarlanan ve kablolar yardımıyla tahrik edilen giyilebilir cihazlar, prensip olarak kullanışlı olmakla birlikte elin doğal hareketine yakın bir egzersiz hareketi sağlamaktan şuan için uzaktırlar ve geliştirilmeleri devam etmektedir. Ayrıca dünya genelinde bu tarz aktif eyleyicili cihazların ticari bir uygulamas bulunmamaktadır.

Son yıllarda Agrawal ve ark. [16, 17], fizik tedavi amaçlı yardımcı (assistive) teknolojiler alanında yaptıkları çalışmalarda hem üst hem de alt ekstremite rehabilitasyonunda kablo ve yay temelli hareket aktarımında başarılı sonuçlar elde etmişlerdir. Kablo ve yay temelli sistemlerin avantajları ağırlığın büyük oranda azaltılması, boyutların küçülmesi ve kontrolün yay ve kablo tahrikli, giyilebilir bir cihaz önerilmektedir. Elektrik enerjisi ile çalışacak cihazın ev ortamında kullanıma uygun ve taşınabilir özellikte olması beklenmektedir. İlerleyen bölümlerde tasarım parametreleri için ihtiyaçların belirlenmesi, cihazın yapısı, aktif eyleyicisinin seçimi, yay sisteminin tasarımı ve yapılacak egzersiz hareketleri açıklanmıştır. Geliștirilecek olan cihazın el rehabilitasyonuna ve tıbbi cihaz sektöründe dış pazarlara bağımlı ülkemizin rekabet gücüne katkı yapacağı düşünülmektedir.

\section{MATERYAL VE YÖNTEM (MATERIAL AND METHOD)}

\section{1. İhtiyaçların Belirlenmesi (Determining The} Requirements)

Bir tasarım işlemi öncelikle ihtiyaçların belirlenmesi ile başlamaktadır. Ardından bu ihtiyaçları karşılayacak fonksiyon yapıları oluşturulur ve çözüm için seçenekler belirlenir. Son olarak en uygun çözüm seçeneği tespit edilir. Daha sonra bu çözüm, bir takım kısıtlamalar (teknolojik, ekonomik, hukuksal vb.) göz önüne alınarak detaylandırılır [18]. 
Cihazın amacına uygun olarak hizmet edebilmesi için kullanıcıların, hekimlerin, fizyoterapistlerin ve bu alandaki yönetmeliklerin [19] beklentilerini karşılaması gerekmektedir. Bu beklentiler doğrultusunda belirlenen ihtiyaç listesi Çizelge 2'de yer almaktadır. bağlantısını yapar sonra ön kol bağlantısını gerçekleştirir. Ayarlanabilir bantlar sayesinde cihaz, el ve ön kol bölgesine sabitlenir. Doğrusal eyleyicinin çalışma şartları (hız, kurs boyu, konum, kuvvet) kontrol birimi vasitasiyla ayarlanmaktadir.

Çizelge 2. El bileği egzersiz cihazı için ihtiyaç listesi (Requirement list of the wrist exercise device)

\begin{tabular}{|c|c|}
\hline $\begin{array}{ll}\text { 1. Geometrik özellikler } \\
\text { - } & \text { Her yetişkin kullanıcının antropometrik } \\
& \text { özelliklerine uygunluk } \\
\text { - } & \text { Ele kolayca giyilip çıkarılma } \\
\text { - } & \text { Hafiflik } \\
\text { - } & \text { Başkasının yardımına gerek duyulmadan } \\
& \text { kullanım } \\
\text { - } & \text { Taşınabilirlik } \\
\text { - } & \text { Ev ortamında kullanılabilirlik } \\
\text { - } & \text { Ergonomiklik } \\
& \\
\text { 2. Kinematik ve kuvvetler } \\
\text { - } & \text { Düşük serbestlik derecesi } \\
\text { - } & \text { El bileğinde minimum kesme kuvveti } \\
\text { - } & \text { Aktif ve pasif egzersizler sağlamak }\end{array}$ & 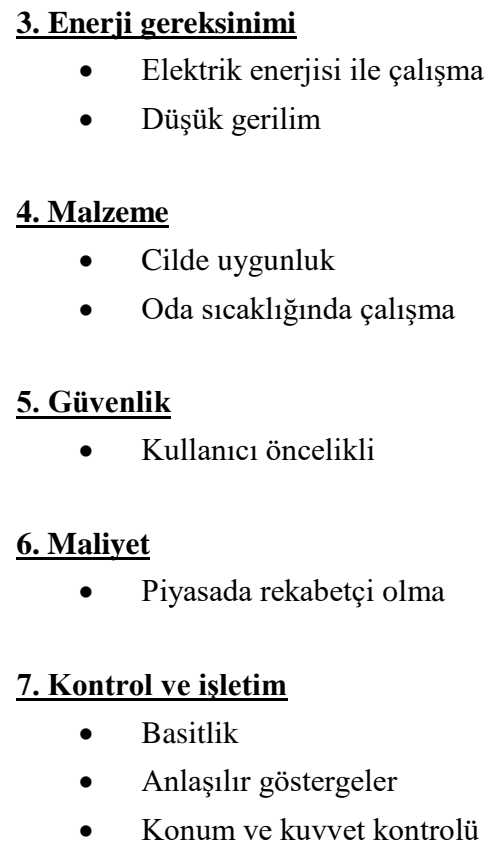 \\
\hline
\end{tabular}

Çizelge 2'de belirlenen ihtiyaçlar arasında, birinci ve ikinci maddelerde sıralananlar bir bakıma rehabilitasyon amaçlı geliştirilen cihazlardaki genel beklentiyi yansıtmaktadır. Bu çalışmada önerilen cihaz açısından bakıldığında, her yetişkinin farklı ölçülerdeki el ve ön kol bölgesine tam olarak uyan bir cihaz ortaya koyabilmek için kişiye özel cihaz üretilmesi düşünülmüştür. El bileği, avuç içi ve ön kol bölgesi üzerinde yapılan birkaç ölçüme göre kişiye özel bir cihazın bileşenleri, üç boyutlu katmanlı üretim yöntemi kullanılarak imal edilmektedir. Sökülüp takılabilen bantlar kullanılarak cihazın giyilip çıkarılması kolaylaştırılmıştır. Cihaz az sayıda bileşenden meydana geleceğinden el üzerine giyilen kısmının ağırlığının 300 gramı geçmemesi beklenmektedir. El bileğinde meydana gelebilecek kesme kuvvetlerini engellemek için özel bir yay sistemi tasarlanmıştır. Ayrıca aktif eyleyicinin çalışma şartları hem pasif hem de aktif egzersize imkân verecek şekilde belirlenmiştir.

\subsection{Cihazın Genel Yapısı (General Structure Of The Device)}

Belirlenen ihtiyaçları karşılayacak şekilde tasarlanan cihazın genel yapısı ve bileşenleri Şekil 1'de görülmektedir. Cihaz, genel olarak ön kol desteği, bilek desteği, el tespit desteği, doğrusal eyleyici, çekme kablosu ve kontrol biriminden meydana gelmektedir. Doğrusal eyleyici, ön kol desteği üzerine sabitlenmiştir. Yay sisteminin bir ucu ön kol, diğer ucu el üzerinde yer almaktadır. Kullanıcı, cihazı önce el üzerine yerleştirerek

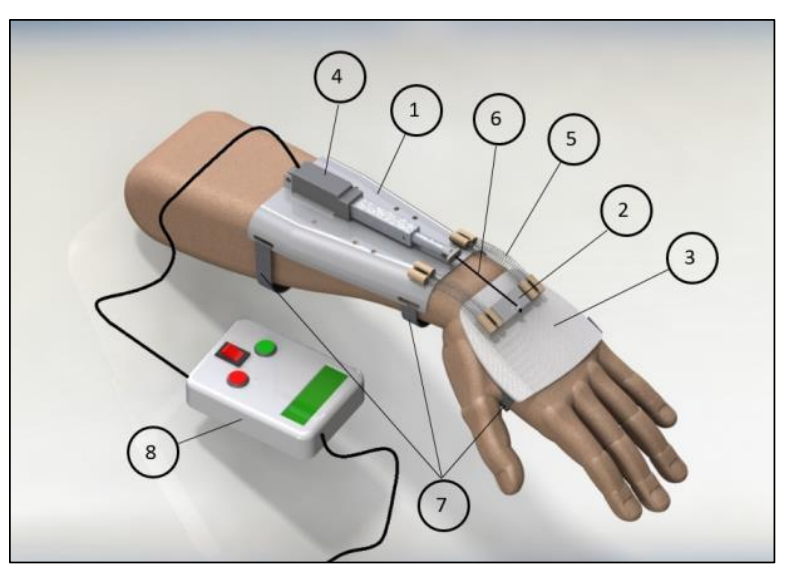

Şekil 1. Önerilen cihazın genel yapısı ve bileșenleri. 1; ön kol desteği, 2; bilek desteği, 3; el tespit desteği, 4; doğrusal eyleyici, 5; yay sistemi, 6; çekme kablosu, 7; ayar bantları, 8; kontrol birimi (General structure and components of the device. 1; forearm support, 2; wrist support, 3; hand support, 4; linear actuator, 5; spring system, 6; pulling cable, 7; adjustable strap, 8 ; control unit)

Serbest ve ark. önceki çalışmalarında [20] el bileğinin ekstansiyon - fleksiyon hareketini incelemişler ve hareket esnasında el bileğinde meydana gelen moment değişiminin $0.37-0.54 \mathrm{Nm}$ arasında olduğunu hesaplamışlardır. Ayrıca el bileğinin normal hareketi sırasındaki eklem açıklığının yaklaşık $40^{\circ}$ ekstansiyon ve yaklaşık $40^{\circ}$ fleksiyon aralığında olduğu bilinmektedir 
$[20,21]$. Bu veriler dikkate alınarak cihazda kullanılacak doğrusal eyleyici için Firgelli firması tarafinda üretilen L16 P serisi bir lineer aktüatör seçilmiştir.

\subsection{Yay Sisteminin Tasarımı (Design Of The Spring Mechanism)}

El bileğinin ekstansiyon - fleksiyon hareketi yay sistemi sayesinde sağlanmaktadır. Yaylar, el bileğini başlangıçta fleksiyon konumunda tutacak şeklinde tasarlanmıştır. İnme rahatsızlığı yaşayan kişilerde görülen spastisiteden dolayı el bileği sürekli olarak fleksiyon konumunda kalmaktadır. Dolayısıyla egzersiz açısında daha önemli olan hareket, el bileğinin ekstansiyonudur.

El bileğini fleksiyonda tutabilecek seviyede kuvvet üreten bir yay belirleyebilmek için çok sayıda deneme yapılmıştır. Denemelerde ticari olarak satılan standart basma yayları kullanılmıştır. Sonuçta Çizelge 3'de özellikleri yer alan standart bir basma yayı seçilmiştir.

Çizelge 3. Cihazda kullanılan basma yayının özellikleri (Specifications of the compression spring using the device)

\begin{tabular}{|l|r|l|}
\hline Tel çap1 & $\mathrm{d}$ & $0.8 \mathrm{~mm}$ \\
\hline Ortalama çap1 & Dm & $5.60 \mathrm{~mm}$ \\
\hline Tam boyu & Lo & $59.00 \mathrm{~mm}$ \\
\hline Minimum boyu & Ln & $27.03 \mathrm{~mm}$ \\
\hline Yay katsayis1 & $\mathrm{C}$ & $0.80 \mathrm{~N} / \mathrm{mm}$ \\
\hline Maksimum kuvvet & $\mathrm{F}$ & $25.59 \mathrm{~N}$ \\
\hline Malzeme & & $\begin{array}{l}\text { Paslanmaz yay } \\
\text { çeliği }\end{array}$ \\
\hline
\end{tabular}

Basma yayları, el bileğini fleksiyon konumunda tutabilmek için bükülmüştür. Yaylar, eğrisel bir kılavuz parça üzerine geçirilerek 1sitılıp soğutulmuştur. Böylece yaylara istenen şekilsel özellik kazandırılmıştır (Şekil 2). Bükülen iki yay uç uca eklenerek tek sıralı bir yapı elde edilmiştir. Cihaz üzerinde toplam dört sıra yay kullanılarak gerekli fleksiyon kuvveti sağlanmıştır.

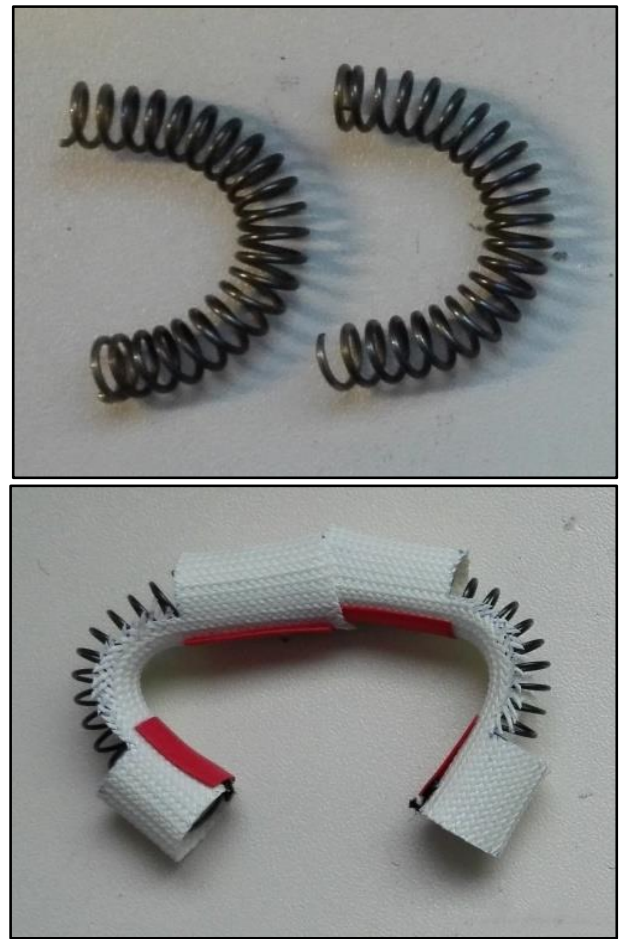

Şekil 2.Solda; bükülmüş yaylar, sağda; uç uca eklenmiş iki yay (Top; twisted springs, bottom; two springs attached to each other)

\subsection{Egzersiz Hareketleri (Exercise Movements)}

El bileği eklemi, iki farklı düzlemde hareket edebilmektedir. Bunlar biri frontal düzlemdeki abdüksiyon - addüksiyon, diğeri sagital düzlemdeki ekstansiyon - fleksiyon hareketidir. Ayrica bu iki hareketin kombinasyonu da mümkündür [8]. Ancak abdüksiyon - addüksiyon hareketinin açıklığı çok azdır. $\mathrm{Bu}$ durum dikkate alınarak cihazın sadece ekstansiyon fleksiyon egzersizlerini gerçekleştirmesi amaçlanmıştır.

Cihazda yer alan yay sistemi, eli başlangıçta fleksiyon konumunda tutmaktadır (Şekil 3. A). Cihaz çalıştırıldığında doğrusal eyleyici negatif hareket yapar (geri doğru hareket). Eyleyiciye bağlı çekme kablosunun yay kuvvetini yenmesi sayesinde el, fleksiyon konumundan ekstansiyon konumuna hareket eder (Sekil 3. B). Cihaz maksimum ekstansiyon konumuna geldikten sonra eyleyici pozitif hareketine (ileriye doğru hareket) başlar. Bu sırada kablo üzerindeki kuvvet yay kuvvetinin altında olacağından el, yay kuvvetinin etkisi ile tekrar fleksiyon konumuna geri döner. $\mathrm{Bu}$ işlemler bir biri ardına tekrarlanarak el bileğine ekstansiyon - fleksiyon egzersizi yaptırılmış olur. 


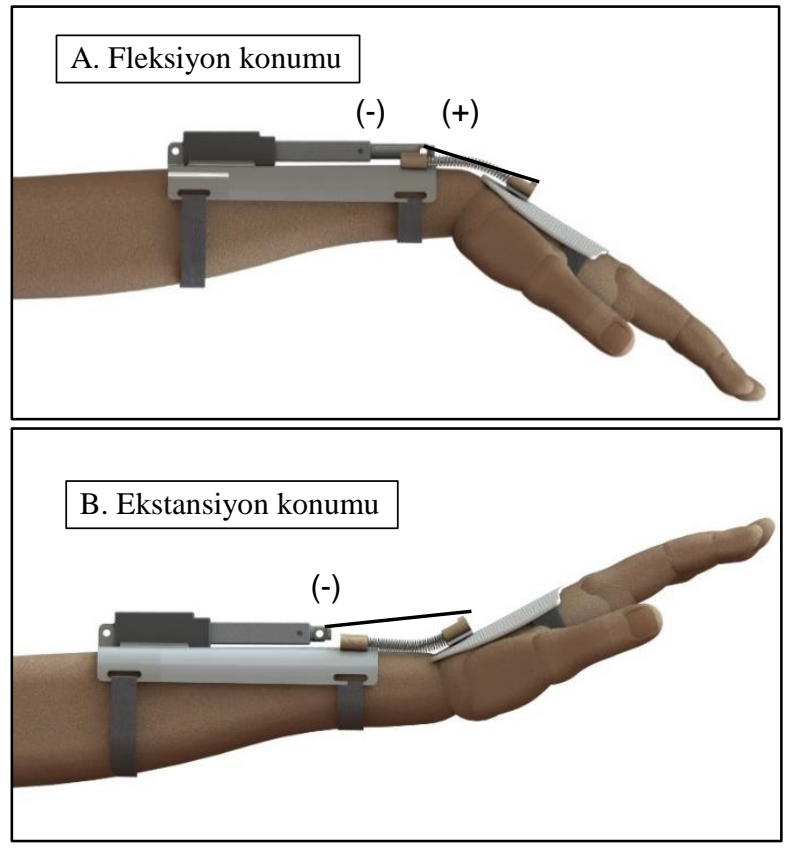

Şekil 3. Egzersiz hareketleri (Exercise movement)

Kontrol birimi ile eyleyicinin kurs boyu ayarlanarak eklem açıklığı artırılıp azaltılabilir. Rehabilitasyon sürecinin başlangıcında daha küçük açıklıkta egzersizler yapılırken, ilerleyen dönemlerde daha büyük eklem açıklığında egzersizler yapılabilir. Ayrıca eyleyicinin ürettiği kuvvet ayarlanabilmektedir. Rehabilitasyon sürecinin ilerleyen dönemlerinde hastalar kaslarını kontrol edebilir hale geldiklerinde, cihazın uyguladığ kuvvet azaltılarak hastanın büyük oranda kendi gücüyle gerçekleştirdiği aktif egzersizler yapılabilir.

\section{SONUÇ ve TARTIŞMA (RESULTS and DISCUSSION)}

Çalışma kapsamında önerilen cihazın, özellikle inme sonrası el rehabilitasyonunda kullanılması amaçlanmıştır. Bunun yanı sıra cihaz, rehabilitasyon ve egzersiz amaçlı diğer uygulamalarda da (sinir yaralanması, sinir sıkışması, tendon yaralanması, kırıklar, spor yaralanmaları, vb.) kullanılabilir. Cihaz, ev ortamında kullanılabilecek özelliklerde olduğundan rehabilitasyon merkezine sürekli gidip gelme zorunluluğu ortadan kalkacaktır. Ayrıca hasta, cihazı istediği zaman kullanarak yüksek yogunluklu egzersizler yapabilecektir. Bu sayede iyileşme süreci hızlanacaktır. Cihaz hem pasif (hasta katılımı olmayan, tamamen cihaz destekli) hem de aktif (hareket için gerekli kuvvetin bir kısmının cihaz, bir kısmının hasta tarafindan sağlanması) egzersizler sağlayarak rehabilitasyon sürecini k1saltabilecek niteliktedir.

Tasarım açısından bakıldığında cihazın en önemli yeniliği kuvvet ve hareket aktarımında ticari basma yayları ve kablo sisteminin kullanılmış olmasıdır. El bileği üzerinde herhangi bir mekanik mafsal ve mekanizma kullanılmadığından el bileğini zorlayıcı kesme kuvvetlerinin oluşumu engellenmiştir. Bunun yanı sıra cihazın bileşenleri dikey doğrultuda fazla yer kaplamadığından cihaz, diğer tasarımlara kıyasla daha estetik görünmektedir. Ele giyilen kısımda az sayıda bileşen bulunmasından dolayı ağırlık bakımından hafif olması beklenmektedir.

Üretilecek cihazın bir diğer olumlu yönü düşük maliyetli olmasıdır. Maliyeti en fazla olan bileşen, cihazın doğrusal eyleyicisidir. Eyleyicinin perakende satış fiyatı 80 \$ civarındadır. Diğer bileşenlerde hesaba katıldığında cihazın rahatlıkla 500 TL'nin altında bir fiyata üretilmesi mümkündür. Bioness firması tarafindan el rehabilitasyonunda kişisel kullanım için geliştirilen cihazın Ülkemizde $8000 \quad €$ 'ya, Rehab-Robotics tarafindan rehabilitasyon merkezleri ve hastaneler için geliştirilen Hand of Hope isimli cihazın da Ülkemizde 70.000 \$'1n üzerinde bir fiyatla satıldığı göz önünde bulundurulduğunda geliştirilen cihazın maliyet açısından son derece rekabetçi olduğu anlaşılmaktadır.

Cihazın üretimi büyük oranda tamamlanmış bulunmaktadır. Cihazın hastalar tarafından kullanılabilmesini sağlamak ve etkinliğini gözlemleyebilmek için Sakarya Üniversitesi Etik Kuruluna başvuru yapılmıştır. Bunun yanı sıra, aynı prensiple çalışacak ve parmak egzersizlerini de sağlayacak el - el bileği egzersiz cihazının tasarım çalışmaları tamamlanmış bulunmaktadır. Bu doğrultuda sınai mülkiyet haklarının tescil işlemleri Türk Patent Enstitüsü nezdinde başlatılmıştır.

\section{TEŞEKKÜR (ACKNOWLEDGEMENT)}

$\mathrm{Bu}$ çalışma Sakarya Üniversitesi Bilimsel Araştırma Projeleri Komisyonu tarafından desteklenmiştir (Proje no: 2014-09-18-001 ve Proje no: 2014-50-02-032). Ayrıca çalışmaya, fizik tedavi ve rehabilitasyon alanındaki tecrübelerini bizlerle paylaşarak katk1 sağlayan Sakarya Üniversitesi Tıp Fakültesi Romatoloji Bilim Dalında görevli Prof. Dr. İbrahim TEKEOĞLU'na teşekkür ederiz.

\section{KAYNAKLAR (REFERENCES)}

1. http://www.world-stroke.org/advocacy/world-strokecampaign, Son Erişim Tarihi: Nisan 2016.

2. WHO (World Health Organization), "World Report on Disability", (2011).

3. Butler J. A., Bay C., Wu D., Richards K. M., Buchanan S. and Yepes M., "Expanding Tele-rehabilitation of Stroke Through In-home Robot-assisted Therapy”, Int J Phys Med Rehabil, 2: 1-11, (2014).

4. Kwakkel G., Wagenaar R. C., Koelman T. W., Lankhorst G. J. and Koetsier J. C., "Effects of intensity of rehabilitation after stroke a research synthesis," Stroke, 28(8): 1550-1556, (1997).

5. Amirabdollahian F., Ateş S., Basteris A., Cesario A., Buurke J., Hermens H., vd., "Design, development and deployment of a hand/wrist exoskeleton for home-based rehabilitation after stroke - SCRIPT project", Robotica, 32(08): 1331-1346, (2014).

6. Heo P., Gu M. G., Lee S., Rhee K. andKim J., "Current hand exoskeleton technologies for rehabilitation and 
assistive engineering", International Journal of Precision Engineering and Manufacturing, 13(5): 807-824, (2012).

7. Iqbal J. and Baizid K., "Stroke rehabilitation using exoskeleton-based robotic exercises: Mini Review", Biomedical Research, 26(1): 197-201, (2015).

8. Nordin M. and Frankel V. H., "Basic biomechanics of the musculoskeletal system”, Lippincott Williams \& Wilkins, (2012).

9. Worsnoop T. T., Peshkin M. A., Colgate J. E. and Kamper D. G., "An Actuated Finger Exoskeleton for Hand Rehabilitation Following Stroke", IEEE $1^{\text {th }}$ International Conference on Rehabilitation Robotics, Netherlands, 896901, (2007).

10. Fontana M., Dettori A., Salsedo F. and Bergamasco M., "Mechanical design of a novel Hand Exoskeleton for accurate force displaying", IEEE International Conference on Robotics and Automation, Japan, 17041709, (2009).

11. Wege A. and G. Hommel G., "Development and control of a hand exoskeleton for rehabilitation of hand injuries", IEEE/RSJ International Conference on Intelligent Robots and Systems, Canada, 3046-3051, (2005).

12. In H. K., Cho K. J., Kim K. R. and Lee B. S., "Jointless structure and under-actuation mechanism for compact hand exoskeleton", IEEE International Conference on Rehabilitation Robotics, Switzerland, 1-6, (2011).

13. Kadowaki Y., Noritsugu T., Takaiwa M., Sasaki D. and Kato M., "Development of Soft Power-Assist Glove and Control Based on Human Intent", Journal of Robotics and Mechatronics, 23(2): 281-291, (2011).
14. Stergiopoulus P., Fuchs P. and Laurgeau C., "Design of a 2-finger hand exoskeleton for VR grasping simulation", Proceedings of the Eurohaptics, Dublin, 80-93, (2003).

15. Polygerinos P., Wang Z., Galloway K. C., Wood R. J. and Walsh C. J., "Soft robotic glove for combined assistance and at-home rehabilitation", Robotics and Autonomous, 73: 135-143, (2015).

16. Duan Q., Vashita V. and Agrawal S. K., "Effect on wrenchfeasible workspace of cable-driven parallel robots by adding springs", Mechanism and Machine Theory, 86: 201-210, (2015).

17. Mao Y., Jin X., Dutta G. G., Scholz J. P. andAgrawal S. K., "Human movement training with a cable driven arm exoskeleton (CAREX)", IEEE Transactions on Neural Systems and Rehabilitation Engineering, 23(1): 84-92, (2015).

18. Pahl G., Beitz W., Feldhusen J., Grote K. H., "Engineering Design", Springer-Verlag, (2007).

19. Sağlık Bakanlığı, "Tıbbi Cihaz Yönetmeliği”, Resmi Gazete Sayısı: 27957, (2011).

20. Serbest K., Eldoğan O., Yıldız M. Z. and Çilli M., "El bileğinin ekstansiyon ve fleksiyon hareketinin analizi için biyomekanik model geliştirilmesi”, 18. Biyomedikal Mühendisliği Ulusal Toplantısı, İstanbul, 1-4, (2014).

21. Ryu J., Cooney W. P., Askew L. J., An K. and Chao E. Y. S., "Functional ranges of motion of the wrist joint", The Journal of Hand Surgery, 16(3): 409-419, (1991).

22. http://www.tevema-industrialsprings.com/Compression_Springs_en.html, Son Erişim Tarihi: Ekim 2017 